\title{
DNA repair gene XRCC3 Thr241Met polymorphism and susceptibility to glioma: A case-control study
}

\author{
GAOFENG XU, MAODE WANG, WANFU XIE and XIAOBIN BAI \\ Department of Neurosurgery, The First Affiliated Hospital of The Medical School of Xi'an Jiaotong University, \\ Xi'an, Shaanxi 710061, P.R. China
}

Received September 19, 2013; Accepted March 28, 2014

DOI: $10.3892 / \mathrm{ol} .2014 .2192$

\begin{abstract}
The DNA repair gene, X-ray repair cross-complementing group 3 (XRCC3) Thr241Met polymorphism may be associated with a susceptibility to glioma. The present study aimed to investigate the association between the XRCC3 Thr241Met polymorphism and the potential susceptibility to gliomas. A hospital-based case-control study was conducted, which included a total of 886 patients with glioma and 886 healthy control subjects. Peripheral blood samples were extracted and the polymerase chain reaction-restriction fragment length polymorphism method was performed to analyze the genotypes. The glioma patients had a significantly higher frequency of the XRCC3 241 MetMet genotype [odds ratio $(\mathrm{OR})=1.62 ; 95 \%$ confidence interval $(\mathrm{CI}): 1.09-2.41 ; \mathrm{P}=0.02]$ compared with the control subjects. When stratified by the grade of the glioma, the patients with stage IV glioma (according to the World Health Organization classification) had a significantly higher frequency of the XRCC3 241 MetMet genotype (OR=1.61; 95\% CI: 1.06-2.44; $\mathrm{P}=0.03$ ). When stratified by the histology of the glioma, there was no significant difference in the distribution of each genotype. The findings of the present study indicate that the XRCC3 Thr241Met polymorphism is associated with a susceptibility to glioma.
\end{abstract}

\section{Introduction}

Gliomas account for $>70 \%$ of all types of brain tumor (1). The estimated five-year survival rate is 60 and $74 \%$ for

Correspondence to: Professor Gaofeng Xu, Department of Neurosurgery, The First Affiliated Hospital of The Medical School of Xi'an Jiaotong University, 277 Yanta West Road, Xi'an, Shaanxi 710061, P.R. China

E-mail: gfxu72@hotmail.com

Abbreviations: XRCC3, X-ray repair cross-complementing group 3; PCR, polymerase chain reaction; OR, odds ratio; CI, confidence interval; GWAS, genome-wide association studies; SNPs, single-nucleotide polymorphisms

Key words: X-ray repair cross-complementing groups 3, glioma, polymorphism biopsy, and watchful waiting and early resection in low-grade gliomas, respectively $(2,3)$. Gliomas are an enigmatic and heterogeneous disease, the exact etiology of which remains unclear (2). Certain factors are found to affect an individual's glioma risk, such as hereditary genetic disorders (4), obesity during adolescence (5), being tall and exposure to high doses of ionizing radiation (5-8). Certain genome-wide association studies (GWAS) have reported that single nucleotide polymorphisms (SNPs) are associated with glioma susceptibility $(9,10)$. However, the additional factors that contribute to glioma susceptibility require further investigation.

The DNA repair gene, X-ray repair cross-complementing group 3 (XRCC3), is involved in the process of homologous recombination repair for DNA double-strand breaks in order to maintain the stability of the genome (11). As the most common functional SNP, the XRCC3 Thr241Met (rs861539) polymorphism is at codon 241 in exon 7 with a $\mathrm{C}$ to $\mathrm{T}$ transition (12). The XRCC3 Thr241Met polymorphism has been investigated in various types of cancer and the results are mixed (13-17).

Although the association between the XRCC3 Thr241Met polymorphism and glioma risk have been extensively investigated, the currently available results are inconclusive (18-24). Although two meta-analyses have been conducted to investigate this association, conflicting results were yielded $(23,24)$. The present study aimed to investigate the association between the XRCC3 Thr241Met polymorphism and the susceptibility to glioma.

\section{Subjects and methods}

Study population. This hospital-based case-control study was conducted in Northwest China. A total of 886 glioma patients and 886 healthy control subjects were recruited from the Department of Neurosurgery of the First Affiliated Hospital of The Medical School of Xi'an Jiaotong University (Xi'an, China) between January 2008 and January 2013. These subjects were recruited from the same geographical region. Alcohol consumption habits were defined as never (never drinks, or less than once a year), past and current. Smoking habits were defined as never (smoked $<100$ cigarettes in their lifetime), past and current. Tumor type and stage were determined according to the World Health Organization (WHO) criteria (25). Control subjects were matched with the patient group regarding gender, age and duration in education. 
Table I. Characteristics of the glioma and healthy control subjects.

\begin{tabular}{|c|c|c|c|}
\hline Characteristic & Glioma, $\mathrm{n}=886$ & Control, $\mathrm{n}=886$ & P-value \\
\hline \multicolumn{4}{|l|}{ Gender, n (\%) } \\
\hline Male & $487(55.0)$ & $483(54.5)$ & 0.85 \\
\hline Female & $399(45.0)$ & $403(45.5)$ & 0.85 \\
\hline Mean age \pm SD (years) & $41.8 \pm 8.6$ & $42.0 \pm 9.0$ & 0.63 \\
\hline Mean time spent in education $\pm \mathrm{SD}$ (years) ${ }^{\mathrm{a}}$ & $11.5 \pm 2.5$ & $11.6 \pm 2.6$ & 0.41 \\
\hline \multicolumn{4}{|l|}{ Smoker, n $(\%)$} \\
\hline Never & $488(55.1)$ & $480(54.2)$ & 0.84 \\
\hline Past & $89(10.0)$ & $93(10.5)$ & 0.78 \\
\hline Current & $309(34.9)$ & $313(35.3)$ & 0.89 \\
\hline \multicolumn{4}{|l|}{ Alcohol consumption, $\mathrm{n}(\%)$} \\
\hline Never & $530(59.8)$ & $542(61.2)$ & 0.77 \\
\hline Past & $149(16.8)$ & $145(16.4)$ & 0.83 \\
\hline Current & $207(23.4)$ & $199(22.4)$ & 0.72 \\
\hline \multicolumn{4}{|l|}{ Family history of cancer, n (\%) } \\
\hline No & $797(90.0)$ & $795(89.7)$ & 0.88 \\
\hline Yes & $89(10.0)$ & $91(10.3)$ & 0.88 \\
\hline \multicolumn{4}{|l|}{ Histology, n (\%) } \\
\hline Astrocytomas & $655(73.9)$ & & \\
\hline Ependymomas & $143(16.1)$ & & \\
\hline Oligodendrogliomas & $53(6.0)$ & & \\
\hline Mixed gliomas & $35(4.0)$ & & \\
\hline \multicolumn{4}{|l|}{ WHO grade, $\mathrm{n}(\%)$} \\
\hline I & $44(5.0)$ & & \\
\hline II & $326(36.8)$ & & \\
\hline III & $221(24.9)$ & & \\
\hline IV & $295(33.3)$ & & \\
\hline
\end{tabular}

${ }^{a}$ This parameter was included as the time spent in education has been found to collate with living habits. WHO, World Health Organization SD, standard deviation.

Informed consent was obtained from all the participants in the present study and, according to the Declaration of Helsinki, this study was approved by the Institutional Review Board of Xi'an Jiaotong University.

DNA extraction and genotyping. Genomic DNA was extracted from peripheral blood samples by QIAamp DNA blood mini kits (QIAGEN Inc., Valencia, CA, USA) according to the manufacturer's instructions. The XRCC3 Thr241Met polymorphisms were determined via polymerase chain reaction (PCR)-restriction fragment length polymorphism assay (PerkinElmer, Inc., Foster City, CA, USA). The primers were designed as follows: Forward, 5'-GCTGTCTCGGGGCATGGCTC-3'; and reverse, 5'-ACGAGCTCAGGGGTGCAACC-3' to amplify a 208-bp fragment (26). The PCR products were digested overnight with the appropriate restriction enzyme, NlaIII (New England Biolabs, Beverly, MA, USA). The XRCC3 241 Met allele was cut into two fragments of 120 and $88 \mathrm{bp}$, whereas the XRCC3 241Thr allele remained uncut with a length of $208 \mathrm{bp}$. The digested PCR products were resolved on $3 \%$ agarose gel and stained with ethidium bromide for visualization under an ultraviolet light. For quality control, the genotyping analysis was performed blind with regard to the subjects. The selected
PCR-amplified DNA samples were also examined by DNA sequencing to verify the genotyping results.

Statistical analysis. The $\chi^{2}$ test was used to assess for any deviation of the genotype frequencies from Hardy-Weinberg equilibrium and to compare the genotype distributions among glioma patients and healthy control subjects. The crude odds ratios (OR) and adjusted ORs for gender and age with a 95\% confidence interval $(\mathrm{CI})$ were calculated by logistic regression analysis. $\mathrm{P}<0.05$ was considered to indicate a statistically significant difference. SAS statistical software, version 9.1 (SAS Institute Inc., Cary, NC, USA) was used to perform the statistical analyses.

\section{Results}

The clinical characteristics of the patients with glioma and the healthy control subjects are presented in Table I. There were no significant differences identified in the distribution of gender, age, duration in education, smoking, alcohol consumption and family history of cancer (Table I). Among the 886 glioma patients, 655 had astrocytomas, 143 had ependymomas, 53 had oligodendrogliomas and 35 had mixed gliomas. Of these cases, 44 patients had grade I gliomas, 326 had grade II gliomas, 221 
Table II. Genotypes and allele distribution of X-ray repair cross-complementing group $3 \mathrm{Thr} 241$ Met polymorphism among the glioma and healthy control subjects.

\begin{tabular}{lccc}
\hline Genotype & Glioma, n $(\%)$ & Control, n $(\%)$ & OR (95\% CI) \\
\hline ThrThr & $472(53.3)$ & $485(54.7)$ & 1.00 (Reference) \\
ThrMet & $343(38.7)$ & $356(40.2)$ & $0.99(0.82-1.20)$ \\
MetMet & $71(8.0)$ & $45(5.1)$ & $1.62(1.09-2.41)$ \\
Thr allele frequency & $1,287(72.6)$ & $1,326(74.8)$ & 1.00 (Reference) \\
Met allele frequency & $485(27.4)$ & $446(25.2)$ & $1.12(0.97-1.30)$ \\
\hline
\end{tabular}

OR, odds ratio; CI, confidence interval; Thr, threonine; Met, methionine.

Table III. Stratification analysis of X-ray repair cross-complementing group 3 Thr241Met polymorphism in glioma patients.

\begin{tabular}{|c|c|c|c|c|c|c|c|c|c|c|}
\hline \multicolumn{11}{|l|}{ A, Histology } \\
\hline \multirow[b]{2}{*}{ Type } & \multirow[b]{2}{*}{ Cases } & \multicolumn{3}{|c|}{ ThrThr } & \multicolumn{3}{|c|}{ ThrMet } & \multicolumn{3}{|c|}{ MetMet } \\
\hline & & $\mathrm{n}(\%)$ & OR $(95 \% \mathrm{CI})$ & P-value & $\mathrm{n}(\%)$ & OR (95\%CI) & P-value & $\mathrm{n}(\%)$ & OR $(95 \% \mathrm{CI})$ & P-value \\
\hline Astrocytomas & 655 & $348(53.1)$ & $1.00(0.84-1.18)$ & 0.98 & 255 (38.9) & $1.01(0.83-1.22)$ & 0.95 & $52(7.9)$ & $0.99(0.68-1.44)$ & 0.96 \\
\hline Ependymomas & 143 & 77 (53.8) & $1.01(0.75-1.36)$ & 0.94 & $54(37.8)$ & $0.98(0.70-1.37)$ & 0.89 & $12(8.4)$ & $1.05(0.55-1.98)$ & 0.89 \\
\hline Oligodendrogliomas & 53 & $29(54.7)$ & $1.03(0.64-1.64)$ & 0.91 & $20(37.7)$ & $0.98(0.57-1.66)$ & 0.93 & $4(7.6)$ & $0.94(0.33-2.68)$ & 0.91 \\
\hline Mixed gliomas & 35 & $18(51.4)$ & $0.97(0.54-1.72)$ & 0.91 & $14(40.0)$ & $1.03(0.55-1.94)$ & 0.92 & $3(8.6)$ & $1.07(0.32-3.56)$ & 0.91 \\
\hline Total & 886 & $472(53.3)$ & 1.00 (Reference) & & $343(38.7)$ & 1.00 (Reference) & & $71(8.0)$ & 1.00 (Reference) & \\
\hline
\end{tabular}

B, World Health Organization classification

\begin{tabular}{|c|c|c|c|c|c|c|c|c|c|c|}
\hline \multirow[b]{2}{*}{ Grade } & \multirow[b]{2}{*}{ Cases } & \multicolumn{3}{|c|}{ ThrThr } & \multicolumn{3}{|c|}{ ThrMet } & \multicolumn{3}{|c|}{ MetMet } \\
\hline & & $\mathrm{n}(\%)$ & OR $(95 \% \mathrm{CI}) \quad \mathrm{I}$ & P-value & $\mathrm{n}(\%)$ & OR $(95 \% \mathrm{CI})$ & P-value & $\mathrm{n}(\%)$ & OR $(95 \% \mathrm{CI})$ & P-value \\
\hline I & 44 & $23(52.3)$ & $0.98(0.59-1.65)$ & 0.94 & $18(40.9)$ & $1.06(0.60-1.85)$ & 0.85 & $3(6.8)$ & $0.85(0.26-2.81)$ & 0.79 \\
\hline II & 326 & $185(56.8)$ & $1.07(0.86-1.32)$ & 0.56 & $125(38.3)$ & $0.99(0.78-1.26)$ & 0.94 & $16(4.9)$ & $0.61(0.35-1.07)$ & 0.09 \\
\hline III & 221 & $124(56.1)$ & $1.05(0.82-1.35)$ & 0.68 & $83(37.6)$ & $0.97(0.73-1.29)$ & 0.83 & $14(6.3)$ & $0.79(0.44-1.43)$ & 0.44 \\
\hline IV & 295 & $140(47.4)$ & $0.89(0.71-1.12)$ & 0.33 & $117(39.7)$ & $1.02(0.80-1.31)$ & 0.85 & $38(12.9)$ & $1.61(1.06-2.44)$ & 0.03 \\
\hline Total & 886 & $472(53.3)$ & 1.00 (Reference) & & $343(38.7)$ & 1.00 (Reference) & & $71(8.0)$ & 1.00 (Reference) & \\
\hline
\end{tabular}

Thr, threonine; Met, methionine; OR, odds ratio; CI, confidence interval.

had grade III gliomas and 295 had grade IV gliomas (according to the WHO criteria). Genotype and allele frequencies were in Hardy-Weinberg equilibrium in the two groups.

Patients with glioma had a significantly higher frequency of the XRCC3 241 MetMet genotype $(\mathrm{OR}=1.62$; 95\% CI: $1.09-2.41 ; \mathrm{P}=0.02)$ compared with the control subjects (Table II). When stratified by the grade of glioma, patients with stage IV glioma had a significantly higher frequency of the XRCC3 241 MetMet genotype (OR=1.61; 95\% CI: 1.06-2.44; $\mathrm{P}=0.03$; Table III). When stratified by the histology of glioma, there was no significant difference identified in the distribution of each genotype (Table III).

\section{Discussion}

The accumulating genetic evidence concerning the risk of glioma is strongly positive. Previous GWAS have reported that SNPs are associated with glioma susceptibility $(9,10)$. A meta-analysis of 11 case-control studies with 2,404 glioma cases and 6,379 control subjects found that the risk of glioma significantly increased between the GSTP1 A114V genotype and other histopathological gliomas, not including glioblastoma multiforme (27). A meta-analysis of nine case-control studies with 3,146 cases and 4,296 control subjects indicated that the XRCC1 Arg399Gln polymorphism was associated with an increased risk of glioma among Asian individuals and borderline increased risk for glioblastoma among Caucasian individuals, whereas the XRCC1 Arg194Trp/Arg280His polymorphisms may have no affect on the susceptibility of glioma among different ethnicities (24). A systematic literature review and meta-analysis of six case-control studies with 2,362 glioma cases and 3,085 control subjects did not indicate a major role of the XRCC1 Arg399Gln polymorphism in influencing the risk of glioma among Caucasian 
individuals (28). A meta-analysis of 11 case-control studies with 3,810 cases and 6,079 control subjects reported that the XRCC1 Arg399Gln polymorphism was moderately associated with an increased risk of gliomas in Asian individuals, while the XRCC1 Arg194Trp and XRCC1 Arg280His polymorphisms demonstrated no significant affects (29). A meta-analysis of 11 case-control studies with 2,808 glioma cases and 3,114 control subjects identified that the XRCC1 Arg399Gln polymorphism may contribute to the susceptibility to gliomas in Asian individuals (30).

The XRCC3 Thr241Met polymorphism has been investigated in various types of cancer and the findings have been varied. A meta-analysis of 157 case-control studies reported the participation of XRCC3 T241M in the susceptibility for bladder and breast cancer, particularly in Caucasian individuals, and the XRCC3 T241M polymorphism was associated with a decreased risk of lung cancer (31). However, another meta-analysis of 17 case-control studies indicated that the XRCC3 T241M polymorphism was not associated with lung cancer risk, which was a stratified analysis by ethnicity, histology and smoking status (32). A meta-analysis of 15 case-control studies involving 4,475 cases and 6,373 control subjects hypothesized that the XRCC3 Thr241Met polymorphism may modify the risk of colorectal cancer, particularly in Asian individuals (33). Conversely, another meta-analysis of 23 published case-control studies indicated that the XRCC3 Thr241Met polymorphism was not associated with the risk of colorectal cancer (34). A meta-analysis of case-control studies identified that the XRCC3 $241 \mathrm{M}$ allele may act as a head and neck cancer risk factor among all subjects (16). In addition, the XRCC3 241M allele may act as a risk factor for breast cancer (35).

The present study has various major limitations. First, these findings should be interpreted with caution as the study population was from Northwest China, which reduces the potential for confounding from ethnicity and does not permit extrapolation of the results to other ethnic groups. Additionally, since the control subjects were recruited from those individuals who were at hospitals for a routine health examination, there was a certain risk of selection bias. Finally, the interactions between gene-gene, gene-environment and even different polymorphic loci of the same gene may modulate the glioma risk.

In conclusion, the present study indicates that the XRCC3 Thr241Met polymorphism is associated with a susceptibility to glioma. However, further studies within Chinese populations with larger sample sizes are required.

\section{References}

1. Wen PY and Kesari S: Malignant gliomas in adults. N Engl J Med 359: 492-507, 2008.

2. Ohgaki $\mathrm{H}$ and Kleihues P: Epidemiology and etiology of gliomas. Acta Neuropathol 109: 93-108, 2005.

3. Jakola AS, Myrmel KS, Kloster R, et al: Comparison of a strategy favoring early surgical resection vs a strategy favoring watchful waiting in low-grade gliomas. JAMA 308: 1881-1888, 2012.

4. Reuss D and von Deimling A: Hereditary tumor syndromes and gliomas. Recent Results Cancer Res 171: 83-102, 2009.

5. Moore SC, Rajaraman P, Dubrow R, et al: Height, body mass index, and physical activity in relation to glioma risk. Cancer Res 69: 8349-8355, 2009.

6. Kostron H, Swartz MR, Miller DC and Martuza RL: The interaction of hematoporphyrin derivative, light, and ionizing radiation in a rat glioma model. Cancer 57: 964-970, 1986.
7. Hocking B: Occupational exposure to ionizing and non-ionizing radiation and risk of glioma. Occup Med (Lond) 58: 148-149, 2008.

8. Ron E, Modan B, Boice JD Jr, et al: Tumors of the brain and nervous system after radiotherapy in childhood. N Engl J Med 319: 1033-1039, 1988.

9. Shete S, Hosking FJ, Robertson LB, et al: Genome-wide association study identifies five susceptibility loci for glioma. Nat Genet 41: 899-904, 2009.

10. Wrensch M, Jenkins RB, Chang JS, et al: Variants in the CDKN2B and RTEL1 regions are associated with high-grade glioma susceptibility. Nat Genet 41: 905-908, 2009.

11. Griffin CS, Simpson PJ, Wilson CR and Thacker J: Mammalian recombination-repair genes XRCC2 and XRCC3 promote correct chromosome segregation. Nat Cell Biol 2: 757-761, 2000.

12. Shen MR, Jones IM and Mohrenweiser H: Nonconservative amino acid substitution variants exist at polymorphic frequency in DNA repair genes in healthy humans. Cancer Res 58: 604-608, 1998

13. Zhao Y, Deng X, Wang Z, Wang Q and Liu Y: Genetic polymorphisms of DNA repair genes XRCC1 and XRCC3 and risk of colorectal cancer in Chinese population. Asian Pac J Cancer Prev 13: 665-669, 2012.

14. Cheng CX, Xue M, Li K and Li WS: Predictive value of XRCC1 1 and XRCC 3 gene polymorphisms for risk of ovarian cancer death after chemotherapy. Asian Pac J Cancer Prev 13: 2541-2545, 2012.

15. Shaker OG and Sadik NA: Polymorphisms in interleukin-10 and interleukin-28B genes in Egyptian patients with chronic hepatitis $\mathrm{C}$ virus genotype 4 and their effect on the response to pegylated interferon/ribavirin-therapy. J Gastroenterol Hepatol 27: 1842-1849, 2012

16. Yin QH, Liu C, Li L, Zu XY and Wang YJ: Association between the XRCC3 T241M polymorphism and head and neck cancer susceptibility: a meta-analysis of case-control studies. Asian Pac J Cancer Prev 13: 5201-5205, 2012.

17. Zhu X, Zhong Z, Zhang X, et al: DNA repair gene XRCC3 T241M polymorphism and bladder cancer risk in a Chinese population. Genet Test Mol Biomarkers 16: 640-643, 2012.

18. Zhao P, Zou P, Zhao L, et al: Genetic polymorphisms of DNA double-strand break repair pathway genes and glioma susceptibility. BMC Cancer 13: 234, 2013.

19. Pan WR, Li G and Guan JH: Polymorphisms in DNA repair genes and susceptibility to glioma in a chinese population. Int J Mol Sci 14: 3314-3324, 2013.

20. Luo KQ, Mu SQ, Wu ZX, Shi YN and Peng JC: Polymorphisms in DNA repair genes and risk of glioma and meningioma. Asian Pac J Cancer Prev 14: 449-452, 2013.

21. Kiuru A, Lindholm C, Heinävaara S, et al: XRCC1 and XRCC3 variants and risk of glioma and meningioma. J Neurooncol 88: 135-142, 2008.

22. Wang LE, Bondy ML, Shen H, et al: Polymorphisms of DNA repair genes and risk of glioma. Cancer Res 64: 5560-5563, 2004.

23. Zhao B, Ye J, Li B, Ma Q, Su G and Han R: DNA repair gene XRCC3 Thr241Met polymorphism and glioma risk: a meta-analysis. Int J Clin Exp Med 6: 438-443, 2013.

24. Jiang J, Quan XF,Zhang L and Wang YC: The XRCC3 Thr241Met polymorphism influences glioma risk - a meta-analysis. Asian Pac J Cancer Prev 14: 3169-3173, 2013.

25. Louis DN, Ohgaki H, Wiestler OD, Cavenee WK, Burger PC, et al: The 2007 WHO classification of tumours of the central nervous system. Acta Neuropathol 114: 97-109, 2007.

26. Duan Z, Shen H, Lee JE, et al: DNA repair gene XRCC3 $241 \mathrm{Met}$ variant is not associated with risk of cutaneous malignant melanoma. Cancer Epidemiol Biomarkers Prev 11: 1142-1143, 2002

27. Fan Z, Wu Y, Shen J and Zhan R: Glutathione S-transferase M1, T1, and P1 polymorphisms and risk of glioma: a meta-analysis. Mol Biol Rep 40: 1641-1650, 2013.

28. Jacobs DI and Bracken MB: Association between XRCC1 polymorphism $399 \mathrm{G} \rightarrow \mathrm{A}$ and glioma among Caucasians: a systematic review and meta-analysis. BMC Med Genet 13: 97 , 2012.

29. Sun JY, Zhang CY, Zhang ZJ, et al: Association between $\mathrm{XRCC} 1$ gene polymorphisms and risk of glioma development: a meta-analysis. Asian Pac J Cancer Prev 13: 4783-4788, 2012.

30. Wei X, Chen D and Lv T: A functional polymorphism in XRCC1 is associated with glioma risk: evidence from a meta-analysis. Mol Biol Rep 40: 567-572, 2013. 
31. Fan W, Li S, Chen Q, Huang Z, Ma Q and Xiao Z: Association between interleukin-10 promoter polymorphisms and endometriosis: a meta-analysis. Gene 515: 49-55, 2013.

32. Zhan P, Wang Q, Qian Q and Yu LK: XRCC3 Thr241Met gene polymorphisms and lung cancer risk: a meta-analysis. J Exp Clin Cancer Res 32: 1, 2013.

33. Wang Z and Zhang W: Association between XRCC3 Thr241Met polymorphism and colorectal cancer risk. Tumour Biol 34 1421-1429, 2013.
34. Zhu H, Lei X, Liu Q and Wang Y: Interleukin-10-1082A/G polymorphism and inflammatory bowel disease susceptibility: a meta-analysis based on 17,585 subjects. Cytokine 61: 146-153,2013.

35. Li D, He Q, Li R, Xu X, Chen B and Xie A: Interleukin-10 promoter polymorphisms in Chinese patients with Parkinson's disease. Neurosci Lett 513: 183-186, 2012. 